\title{
Risk Assessment of Mycotoxins in Staple Foods from the High-Risk Area for Human Esophageal Cancer in China
}

\author{
Takumi Yoshizawa and Hong-Ping Gao
}

\begin{abstract}
We attempted to estimate whether mycotoxins might account for the increased risk of human esophageal cancer (HEC) in Henan province, China. Corn and wheat as staple foods were collected in 1989, 1995 and 1997 from Linxian and Shangqiu counties, the high- and low-risk areas of HEC in Henan, respectively, and analyzed for the occurrence of trichothecenes, fumonisins, zearalenone and aflatoxin $B_{1}$. Among these mycotoxins examined, fumonisin $\mathrm{B}_{1}\left(\mathrm{FB}_{1}\right)$ and deoxynivalenol $(\mathrm{DON})$ were major toxins exposing populations in both areas through corn consumption.

According to the risk assessment of $\mathrm{FB}_{1}$ and $\mathrm{DON}$ in both areas based on their levels in the staples, the estimated probable daily intake (PDI) values of $\mathrm{FB}_{1}$ and $\mathrm{DON}$ for the high-risk area were 1.6 to 1.9 and 4.9 to 9.2 times higher, respectively, than those for the low-risk area. As compared with the tolerable daily intake (TDI) values of $\mathrm{FB}_{1}$, which is estimated $800 \mathrm{ng} / \mathrm{kg}$ bw per day based on the published toxicological data, PDI values of $\mathrm{FB}_{1}$ especially in 1995 and 1997 for both areas were 3.0 to 6.8 times of the TDI value. The PDI value of DON for the high-risk area was above its TDI (1,000 ng/ kg bw per day) in 1989 and 1995, whereas the PDI for the low-risk area was below the TDI in three years. The results obtained in the present study hardly support the hypothesis that $\mathrm{FB}_{1}$ contamination increases the risk of HEC in Henan province, China. Considering HEC as a multifactorial disease, however, $\mathrm{FB}_{1}$ as well as DON may be considered to be one of factors involved in HEC.
\end{abstract}

Key words : risk assessment, fumonisin, deoxynivalenol, esophageal cancer, China.

\section{Introduction}

The highest incidence areas of human esophageal cancer (HEC) in the world are reported in parts of China, southern Africa and northeastern Iran ${ }^{1)}$. In China, HEC is prevalent in certain provinces that border on the Taihang Mountains in northern China, notably, Henan, Hebei, and Shanxi provinces ${ }^{2}$. In particular, Linxian county in Henan is well-known as the highest risk area, where the average age-adjusted mortality rates per 100,000 were reported as 161 for males and 103 for females.

Etiological studies have indicated that HEC is a multistage and multilfactorial disease. Fungal contamination in foods and exposure to mycotoxins, together with poor nutritional status, deficiency of certain vitamins and trace elements, nitrate and nitrite in drinking water

Department of Biochemistry and Food Science, Faculty of Agriculture, Kagawa University, Miki, Kagawa 761-0795, Japan

Fax : 087-891-3102 
and nitrosamine in foods, and Candida esophagitis have been considered as possible contributory factors in the development of $\mathrm{HEC}^{2)}$. Investigations on the contamination of toxigenic fungi and mycotoxins in cereals from HEC risk areas have been in progress in China and South Africa ${ }^{1,3,4}$. However, so far the correlation between mycotoxins and the incidence of HEC has not yet been clarified.

In regard to mycotoxin contamination in grains from $\mathrm{HEC}$ areas, comparative studies on the natural occurrence of Fusarium mycotoxins (fumonisins, trichothecenes and zearalenone) in corn and wheat from Linxian, the high-risk area and Shangqiu, the low-risk area were carried out in our laboratory ${ }^{5-7)}$. In Transkei, southern Africa, the relationship of Fusarium mycotoxins and HEC has been extensively studied. High concentrations of various Fusarium mycotoxins were found in moldy home-grown corn collected from the high HEC area in Transkei ${ }^{8)}$. Furthermore, fumonisins were found in corn samples from the high-risk area at significantly higher level than those from the low-risk area ${ }^{8,9}$, suggesting an association between the contamination of corn with fumonisins and the incidence of HEC. However, this is contrary to the results previously obtained in China ${ }^{5-7}$.

The present study focused on the occurrence of mycotoxins in staple foods from Linxian and Shangqiu, which lies about $250 \mathrm{~km}$ southeast of Linxian in Henan. By chemical studies on the natural occurrence of mycotoxins in corn and wheat of the subsequent year's harvest from both areas, it might be possible to have a relatively comprehensive knowledge of mycotoxin status in staple foods and to assess the possible association of mycotoxins with the incidence of HEC in China.

\section{Materials and Methods}

\section{Cereal Samples}

A total of 131 corn and 100 wheat samples were obtained by visiting different peasant families in Linxian and Shangqiu counties in 1989, 1995 and 1997. Among these, 76 corn and 65 wheat samples were collected from different HEC-patient families randomly selected in Linxian, whereas 55 corn and 45 wheat samples were from different peasant families with HEC-patient free in Shangqiu. All samples were home-grown and intended for human consumption. Wheat comprises 70 to $80 \%$ of the staple food in both areas, while corn comprises $20 \%$ and 5 to $20 \%$ in Linxian and Shangqiu, respectively. There is not so much difference in recipes as well as means of food processing in both areas.

\section{Analysis of Mycotoxins}

Corn and wheat samples for analyses of Fusarium mycotoxins were extracted according to the procedure described previously ${ }^{5-7}$. Briefly, a ground sample $(20 \mathrm{~g})$ was extracted with acetonitrile-water $(3: 1)$. The filtrate was defatted, and the aqueous acetonitrile layer was divided into two portions chromatographed either on a Florisil column for analysis of trichothecenes and zearalenone or on a strong anion-exchange cartridge (Sep-Pak Accell Plus QMA) for fumonisin analysis. Fumonisins in extracts were derivatized with ophthaldialdehyde and analyzed by HPLC for $\mathrm{FB}_{1}, \mathrm{FB}_{2}$ and $\mathrm{FB}_{3}$ according to the method of Shephard $e t a l^{10)}$, with a slight modification. Trichothecenes were reacted with a trimethylsilylating reagent and determined by GC-MS with a selected ion-monitoring mode. Zearalenone was also analyzed by HPLC. 


\section{Results and Discussion}

\section{Exposure to Fumonisins}

Table 1 shows the incidences and contamination levels of $\mathrm{FB}_{1}, \mathrm{FB}_{2}$ and $\mathrm{FB}_{3}$ in corn samples from the two areas. In three year's surveys, the incidence of total fumonisins in Linxian corn was 1.6 to 1.9 times higher than those in Shangqiu corn. However, similar mean levels of $\mathrm{FB}_{1}$ in positive samples from Linxian and Shangqiu were obtained: 872 and $890 \mathrm{ng} / \mathrm{g}$ in $1989,3,458$ and 3,391 $\mathrm{ng} / \mathrm{g}$ in 1995 and 2,744 and $2.751 \mathrm{ng} / \mathrm{kg}$ in 1997, respectively. The levels of individual fumonisins in corn from both areas were insignificantly different in three year's surveys $(\mathrm{P}>0.05)$.

The distribution of fumonisin contamination in 1995 and 1997 is illustrated in Figure 1. Fumonisins were detected at over $1,000 \mathrm{ng} / \mathrm{g}$ in 44 to $47 \%$ and 30 to $40 \%$ of samples from the two areas in 1995 and 1997, respectively. In addition, heavily contaminated corn samples at over $5,000 \mathrm{ng} / \mathrm{g}$, the level to be suspected of involving in animal intoxications ${ }^{11,12}$, were found in $16 \%$ of Linxian corn and $11 \%$ of Shangqiu corn. The results is a matter of concern in relation to food safety and human health risk, although nothing has been confirmed regarding effects of fumonisins on human population.

\section{Exposure to Trichothecenes}

The natural occurrence of trichothecenes in corn and wheat from the two areas in 1995 and 1997 is shown in Table 2. DON, 15-ADON and NIV were determined in Linxian corn, whereas only DON and NIV were in Shangqiu corn. DON and 15-ADON were major trichothecenes in corn, and their incidences in Linxian were 2.1 to 3.7 times of those in Shangqiu. Their levels were also significantly higher in Linxian corn than those in Shangqiu corn $(\mathrm{P}<0.01)$. Thus, the trichothecenes, especially DON, frequently contaminated corn

Table 1 Natural occurrence of fumonisins in corn from the high- and low-risk areas of HEC in China.

\begin{tabular}{|c|c|c|c|c|c|c|}
\hline \multirow{2}{*}{ Year } & \multirow{2}{*}{ Area } & \multirow{2}{*}{$\begin{array}{c}\% \\
\text { positive }\end{array}$} & \multicolumn{4}{|c|}{ Mean concn. (max.), ng/g } \\
\hline & & & $\mathrm{FB}_{1}$ & $\mathrm{FB}_{2}$ & $\mathrm{FB}_{3}$ & Total \\
\hline \multirow[t]{2}{*}{$1989^{*}$} & High & 48.1 & $\begin{array}{r}872 \\
(2,960)\end{array}$ & $\begin{array}{r}300 \\
(550)\end{array}$ & $-{ }^{* *}$ & - \\
\hline & Low & 25.0 & $\begin{array}{r}890 \\
(1,730)\end{array}$ & $\begin{array}{r}447 \\
(450)\end{array}$ & - & - \\
\hline \multirow[t]{2}{*}{1995} & High & 79.4 & $\begin{array}{r}2,730 \\
(21,000)\end{array}$ & $\begin{array}{r}696 \\
(4,350)\end{array}$ & $\begin{array}{r}384 \\
(1,660)\end{array}$ & $\begin{array}{r}3,458 \\
(27,010)\end{array}$ \\
\hline & Low & 50.0 & $\begin{array}{r}2,702 \\
(8,470)\end{array}$ & $\begin{array}{r}591 \\
(1,220)\end{array}$ & $\begin{array}{r}310 \\
(576)\end{array}$ & $\begin{array}{r}3,391 \\
(10,270)\end{array}$ \\
\hline \multirow[t]{2}{*}{1997} & High & 73.3 & $\begin{array}{r}2,028 \\
(8,290)\end{array}$ & $\begin{array}{r}595 \\
(2,190)\end{array}$ & $\begin{array}{r}276 \\
(1,030)\end{array}$ & $\begin{array}{r}2,744 \\
(11,510)\end{array}$ \\
\hline & Low & 46.7 & $\begin{array}{r}2,082 \\
(5,330)\end{array}$ & $\begin{array}{r}263 \\
(1,210)\end{array}$ & $\begin{array}{r}239 \\
(622)\end{array}$ & $\begin{array}{r}2,751 \\
(7,160)\end{array}$ \\
\hline
\end{tabular}

${ }^{*}$ From Yoshizawa et al.: Appl. Environ. Microbiol.(1994).

** Not examined.

Insignificant difference $(\mathrm{P}>0.05)$ of fumonisin levels between the two areas was found. 


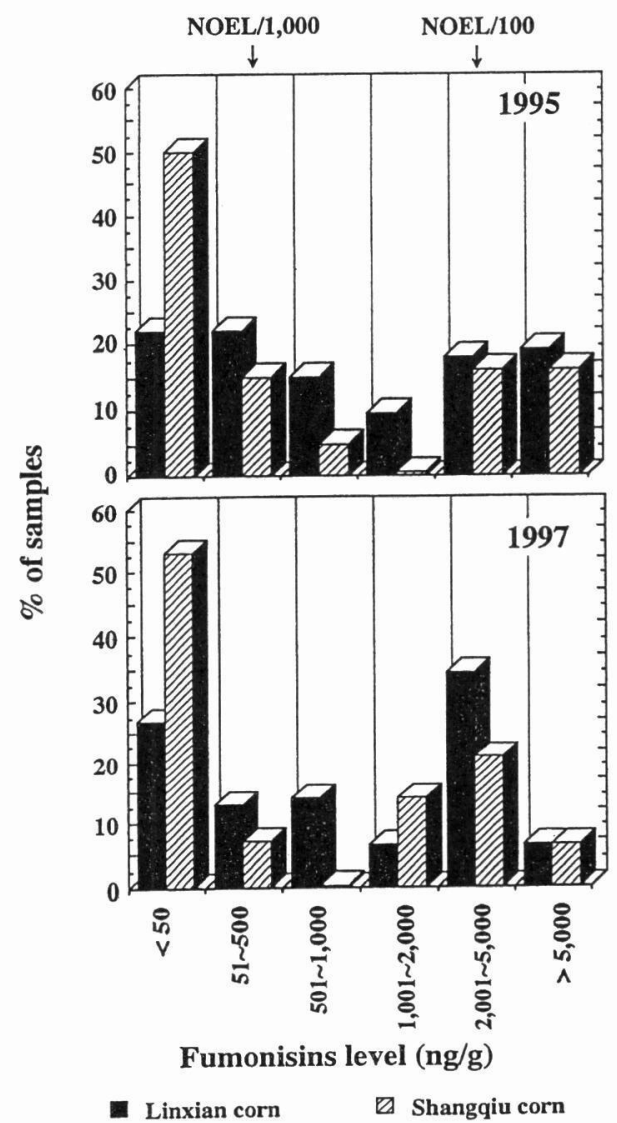

Fig. 1 Distribution of fumonisin levels in corn from the high-and low-risk areas of HEC.

in the high-risk area, which was in good agreement with the previous results ${ }^{5}$.

DON and NIV were detected in wheat samples from both areas, and none of other trichothecenes monitored were found. Incidences of DON and NIV in Linxian were 1.6 and 1.8 times higher, respectively, than those in Shangqiu. Mean levels of DON and NIV were 83 $\mathrm{ng} / \mathrm{kg}$ and $29 \mathrm{ng} / \mathrm{g}$ in Linxian, and $40 \mathrm{ng} / \mathrm{g}$ and $12 \mathrm{ng} / \mathrm{g}$ in Shangqiu, respectively. Although concentrations of DON and NIV in wheat from Linxian were significantly higher than those from Shangqiu ( $\mathrm{P}<0.01$ for $\mathrm{DON} ; \mathrm{P}<0.05$ for NIV), their levels in wheat were below $220 \mathrm{ng} /$ $\mathrm{g}$ and much lower than those in corn. These results suggest that corn is a major source of DON exposure to local populations in the high-risk area.

Although no definitive evidence indicating the involvement of DON and NIV in carcinogenesis is available, there are several reports suggesting this possibility of trichothecenes. Mixtures of trichothecenes were shown to promote esophageal tumors initiated in animals by nitrosamine ${ }^{13)}$. DON was suggested to be a clastogenic tumor formation toxin ${ }^{14)}$. Recently, genotoxicity of NIV was found in cultured cells and multiple mouse organs including the gastrointestinal tract by the alkaline single-cell gel electrophoresis assay ${ }^{15}$. The differences in the incidence and levels of trichothecenes between the two areas confirmed in the present study together with the previous results ${ }^{5)}$ may provide an additional 
Table 2 Occurrence of trichothecenes in corn and wheat from the high- and low-risk areas of HEC in China.

\begin{tabular}{|c|c|c|c|c|c|c|}
\hline \multirow{2}{*}{ Year } & \multirow{2}{*}{ Area } & \multirow{2}{*}{$\begin{array}{c}\% \\
\text { positive }\end{array}$} & \multicolumn{4}{|c|}{ Mean concn. (max.), ng/g } \\
\hline & & & DON & $15-\mathrm{ADON}$ & NIV & Total \\
\hline \multicolumn{7}{|l|}{ Corn } \\
\hline \multirow[t]{4}{*}{1995} & High & 73.5 & 400 & 237 & 86 & 517 \\
\hline & & & $(1,160)$ & (620) & (153) & $(1,780)$ \\
\hline & Low & 20.0 & 51 & nd & 59 & 55 \\
\hline & & & (87) & $(-)$ & (107) & (107) \\
\hline \multirow[t]{4}{*}{1997} & High & 93.3 & 129 & 59 & 59 & 176 \\
\hline & & & (393) & (168) & (75) & $(606)$ \\
\hline & Low & 46.7 & 85 & 45 & 45 & 124 \\
\hline & & & (171) & $(80)$ & (45) & (235) \\
\hline \multicolumn{7}{|l|}{ Wheat } \\
\hline \multirow[t]{4}{*}{1995} & High & 92.0 & 83 & nd & 29 & 87 \\
\hline & & & (193) & $(-)$ & (50) & (218) \\
\hline & Low & 60.0 & 40 & nd & 12 & 40 \\
\hline & & & (125) & $(-)$ & (22) & (125) \\
\hline \multirow[t]{3}{*}{1997} & High & 66.7 & 28 & nd & 95 & 38 \\
\hline & & & (138) & $(-)$ & (95) & (138) \\
\hline & Low & 0.0 & $\begin{array}{l}\text { nd } \\
(-)\end{array}$ & $\begin{array}{l}\text { nd } \\
(-)\end{array}$ & $\begin{array}{r}\text { nd } \\
(-)\end{array}$ & - \\
\hline
\end{tabular}

Significant difference $(\mathrm{P}<0.01)$ of trichothecene levels between the two areas was found in two years.

support for the possible involvement of these mycotoxins in HEC in China.

\section{Exposure to Zearalenone and Aflatoxins}

The incidences of zearalenone in corn from Linxian were 3.5 to 11 times of those in Shangqiu. Its levels in Linxian corn, even below $170 \mathrm{ng} / \mathrm{g}$, were significantly higher than those in Shangqiu corn in both $1995(\mathrm{P}<0.01)$ and $1997(\mathrm{P}<0.05)$, which was in line with that found in 1989's samples ${ }^{5}$. As for wheat, zearalenone was detected at low incidences and levels (below $25 \mathrm{ng} / \mathrm{g}$ ) in Linxian samples but free in Shangqiu samples (data not shown).

As reported by others ${ }^{16,17)}$, aflatoxin B1 was detected at very low levels in both areas in 1995 and 1997 surveys, except one Shangqiu corn $(129 \mathrm{ng} / \mathrm{g})$.

\section{Risk Assessment of Fusarium Mycotoxins}

According to the present study, the major mycotoxins contaminated staple foods in the two areas were fumonisins and trichothecenes, especially $\mathrm{FB}_{1}$ and DON. In order to evaluate the potential health risk of the mycotoxins to the local populations posed by staple consumption, the risk assessment of $\mathrm{FB}_{1}$ and $\mathrm{DON}$ was conducted on the basis of both estimated probable daily intakes (PDI) and tolerable daily intakes (TDI) of these toxins. For this purpose, it was assumed that the daily food intake of an adult of $60 \mathrm{~kg}$ bw is $150 \mathrm{~g}$ for corn and $600 \mathrm{~g}$ for wheat.

\section{Risk Assessment of $\mathbf{F B}_{1}$}

On the basis of the carcinogenicity study of $\mathrm{FB}_{1}$ in rats, its no-observed effect level 
Table 3 Probable daily intake (PDI) of fumonisin $B_{1}$ in the high- and lowrisk areas of $\mathrm{HEC}$ in China.

\begin{tabular}{|c|c|c|c|c|c|}
\hline Year & Area & $\begin{array}{c}\text { No. } \\
\text { sample }\end{array}$ & $\begin{array}{l}\text { Fumonis } \\
\text { Mean* }\end{array}$ & $\begin{array}{c}\mathrm{B}_{1}(\mathrm{ng} / \mathrm{g}) \\
(\max .)\end{array}$ & $\begin{array}{c}\text { PDI } \\
(\mathrm{ng} / \mathrm{kg} \mathrm{bw})^{* *}\end{array}$ \\
\hline \multirow[t]{2}{*}{$1989 * * *$} & High & 27 & 420 & $(2,960)$ & 1,050 \\
\hline & Low & 20 & 223 & $(1,730)$ & 560 \\
\hline \multirow[t]{2}{*}{1995} & High & 34 & 2,170 & $(21,000)$ & 5,430 \\
\hline & Low & 20 & 1,350 & $(8,470)$ & 3,380 \\
\hline \multirow[t]{2}{*}{1997} & High & 15 & 1,490 & $(8,290)$ & 3,730 \\
\hline & Low & 15 & 970 & $(5,330)$ & 2,430 \\
\hline
\end{tabular}

* Mean of all samples analyzed.

** PDI was based on the daily food intake (150 $\mathrm{g}$ corn and $600 \mathrm{~g}$ wheat) per person $(60 \mathrm{~kg}$ bw).

*** Calculated from the data of Yoshizawa et al. (1994).

Table 4 Probable daily intake (PDI) of deoxynivalenol (DON) in the high- and low-risk areas of HEC in China.

\begin{tabular}{|c|c|c|c|c|c|c|}
\hline Year & Area & Food & $\begin{array}{l}\text { No. } \\
\text { sample }\end{array}$ & \multicolumn{2}{|c|}{ DON level (ng/kg) } & $\begin{array}{c}\text { PDI } \\
(\mathrm{ng} / \mathrm{kg} \mathrm{bw})^{* *}\end{array}$ \\
\hline \multirow[t]{6}{*}{$1989^{* * *}$} & \multirow[t]{3}{*}{ High } & corn & 27 & 553 & $(3,505)$ & 1,380 \\
\hline & & wheat & 15 & 28 & (309) & 280 \\
\hline & & & & & & 1,660 \\
\hline & \multirow[t]{3}{*}{ Low } & corn & 20 & 40 & $(612)$ & 100 \\
\hline & & wheat & 15 & 8 & (36) & $\frac{80}{180}$ \\
\hline & & & & & & 180 \\
\hline \multirow{6}{*}{1995} & \multirow{3}{*}{ High } & corn & 34 & 259 & $(1,160)$ & 650 \\
\hline & & wheat & 25 & 70 & (193) & 700 \\
\hline & & & & & & 1,350 \\
\hline & \multirow[t]{3}{*}{ Low } & corn & 20 & 5 & (87) & 10 \\
\hline & & wheat & 15 & 21 & (125) & 210 \\
\hline & & & & & & 220 \\
\hline \multirow[t]{5}{*}{1997} & \multirow[t]{3}{*}{ High } & corn & 15 & 120 & (393) & 300 \\
\hline & & wheat & 15 & 19 & (138) & 190 \\
\hline & & & & & & 490 \\
\hline & \multirow[t]{2}{*}{ Low } & corn & 15 & 40 & (171) & 100 \\
\hline & & wheat & 15 & - & $(-)$ & 0 \\
\hline
\end{tabular}

*,** See the footnote of Table 3.

${ }^{* * *}$ Calculated from the data of Luo et al. (1990).

(NOEL) was estimated to be $0.8 \mathrm{mg} / \mathrm{kg}$ bw per day ${ }^{18)}$. If a safety factor of 1,000 is selected arbitrarily because it is the borderline value for differentiating between toxic and carcinogenic effects ${ }^{18)}$, the calculated TDI (NOEL/safety factor) of $F_{1}$ is $800 \mathrm{ng} / \mathrm{kg}$ bw per day.

The estimated PDI values for Linxian and Shangqiu populations are shown in Table 3. The PDI value for $\mathrm{FB}_{1}$ in Linxian was 1.5 to 1.9 times of those in Shangqiu. Especially, the $\mathrm{PDI}$ values of $\mathrm{FB}_{1}$ in 1995 and 1997 for both populations were 3.0 to 6.8 times of the TDI value (NOEL/1,000). Moreover, for people in the high-risk area who consumed corn contaminat- 
ed with $\mathrm{FB}_{1}$ at a maximum level of $21 \mathrm{mg} / \mathrm{kg}$, the calculated PDI value is $52,500 \mathrm{ng} / \mathrm{kg}$ bw per day, as high as 65.6 times of the TDI.

Thus, the back ground level of $\mathrm{FB}_{1}$ exposure is generally high in Linxian as well as Shangqiu, implying the potential health risk of the toxin to populations of both areas. In addition, because of not so much difference in the PDI values of $\mathrm{FB}_{1}$ between two areas, it is difficult to support the hypothesis that fumonisin contamination increases the risk of HEC in Henan province, China.

\section{Risk Assessment of DON}

In spite of being one of the least acutely toxic trichothecene, frequent contamination of grains with DON is an important human and animal safety issue. Kuiper-Goodman ${ }^{19}$ estimated the TDI of DON to be 3,000 and $1,500 \mathrm{ng} / \mathrm{kg}$ bw per day for adults and infants, respectively. Animal experiments revealed monogastric animals, especially swine and dogs show the greatest sensitivity to DON with the NOEL of $0.1 \mathrm{mg} / \mathrm{kg}$ bw per day ${ }^{20)}$. Evaluation of the hazard potential indicated that DON is unlikely to exhibit specific effects in the absence of general toxicity such as DNA-interaction, reproductive toxicity, neurotoxicity or immunotoxicity. Hence, an uncertainly factor of 100 as a minimum is recommended resulting in the TDI proposal for DON of $1,000 \mathrm{ng} / \mathrm{kg}$ bw per day.

The estimated PDI values of DON for Linxian and Shangqiu populations are shown in Table 4. The PDI of DON for Linxian was 4.9 to 9.2 times of those for Shangqiu in three years' survey. In Linxian, the PDI value for DON was above the TDI in 1989 and 1995, whereas the PDI value for Shangqiu was below the TDI in three years. The results implicated that the human health risk by consuming corn and wheat contaminated with DON is possible for Linxian.

In conclusion, the results obtained in the present study hardly support the hypothesis that $\mathrm{FB}_{1}$ contamination increases the risk of HEC in Henan province, China. Considering HEC as a multifactorial disease, however, $\mathrm{FB}_{1}$ as well as $\mathrm{DON}$ may be considered to be one of factors involved in HEC.

\section{References}

1) Beardall, J. M., Miller, J. D. : Diseases in humans with mycotoxins as possible causes. In "Mycotoxins in Grain Compounds Other Than Aflatoxin” (eds. Miller, J. D., Trenholm, H. L.), p. 487-539 (1994), Eagan Press, St. Paul, MN.

2) Yang, C. S. : Research on esophageal cancer in China. Cancer Res., 40, 2633-2644 (1980).

3) Li, M. H., S. Cheng, S. : Etiology of carcinoma of the esophagus. In "Carcinoma of the Esophagus and Gastric" (esd., Huang, G. J., Wu, Y. K.), p. 26-52 (1984), Springer-Verlag, New York.

4) Marasas, W. F. O., Wehner, F. C., van Rensburg, S. J., van Schalkwyk, D. J. : Mycoflora of corn produced in human esophageal cancer areas in Transkei, southern Africa. Phytopathol., 71, 791-796 (1981).

5) Luo, Y., Yoshizawa, T., Katayama, T. : Comparative study on the natural occurrence of Fusarium mycotoxins (trichothecenes and zearalenpne) in corn and wheat from high- and low-risk areas for human esophageal cancer in China. Appl. Environ. Microbiol., 56, 3723-3726 (1990).

6) Yoshizawa, T., A. Yamashita, A., and Y. Luo. Y.: Fumonisin occurrence in corn from high- and low-risk areas for human esophageal cancer in China. Appl. Environ. Microbiol., 60, 1626-1629 (1994).

7) Gao, H. P., and Yoshizawa, T.: Further studiy on Fusarium mycotoxins in corn and wheat from a high-risk area for human esophageal cancer in China. Mycotoxins, 45, 51-55 (1997). 
8) Sydenham, E. W., Thiel, P. G., Marasas, W. F. O., Shephard, G. S., van Schalkwyk, D. J., Koch, K. R, : Natural occurrence of some Fusarium mycotoxins in corn from low and high csophagcal cancer prevalence areaa of the Transkei, southern Africa. J. Agric. Food Chem., 38, 1900-1903 (1990).

9) Rheeder, J. P., Marasas, W. F. O., Thiel, P. G., Sydenham, E. W., Shephard, G. S., van Schalkwyk, D. J.: Fusarium moniliforme and fumonisins in corn in relation to human esophageal cancer in Transkei. Phytopathol., 82, 353-357 (1992).

10) Shephard, G. S., Sydenham, E. W., Thiel, P. G., Gelderblom W. C. A. : Quantitative determination of fumonisin $B_{1}$ and $B_{2}$ by high-performance liquid chromatography with fluorescence detection. J. Liq. Chromatogra., 13, 2077-2087 (1990).

11) Shephard, G. S., Thiel, P. G., Stockenstrom, S., Sydenham, E. W.: Worldwide survey of fumonisin contamination of corn and corn-based products. J. AOAC Int., 79, 671-687 (1996).

12) Gelderblom, W. C. A., Kriek, N. P. J., Marasas, W. F. O., P. G. Thiel, P. G. : Toxicity and carcinogenicity of the Fusarium moniliforme metabolite, fumonisin $\mathrm{B}_{1}$, in rats. Carcinogenesis, 12, 1247-1251 (1991).

13) van Rensburg, S. J.: Role of mycotoxins in endemic liver ánd esophageal cancer. In "Bioact. Molccules 1 Mycotoxins and Phycotoxins" (eds., Steyn, P. S., Vleggaar, R.), p. 483-494 (1986), Elsevicrs, Amsterdam.

14) Hsia. C. C., Wa. J. L., Lu, X. Q., Li, Y. S. : Natural occurrence and clastogenic effects of myalcnol, dcoxynivalcnol, 3-acctyl-dcoxyniyalcnol, 15-acctyl-deoxynivalenol, and zearalenone in corn from a high risk area of esophageal cancer. Cancer Detect. Prev., 13, 79-86 (1988).

15) Tsuda, S., Kosaka, Y., Murakami, M., Matsuo, H., Matsusaka, N., Taniguchi, K., Sasaki, Y.: Detection of nivalenol genotoxicity in cultured cells and multiple mouse organs by the alkaline single-cell gel electrophoresis assay. Mutat. Res., 415, 191-200 (1998).

16) Chu, F. S., Li, G. Y.: Simultaneous occurrence of fumonisin $B_{1}$ and other mycotoxins in moldy corn collected from the People's Republic of China in regions with high incidences of esophageal cancer. Appl. Environ. Microbiol, 60 : 847-852 (1994).

17) Zhang, H., Nagashima, H., Goto, T. : Natural occurrence of mycotoxins in corn, samples from high and low risk areas for human esophageal cancer in China Mycotoxins, 44, 29-35 (1996).

18) Marasas, W. F. O.: Risk assessment of fumonisins produced by Fusarium moniliforme in corn. Cereal Research Communications, 25, 399-406 (1997).

19) Kuiper-Goodman, T.: Prevention of human mycotoxicoses through risk assessment and risk management. In "Mycotoxins in Grain Compounds Other Than Aflatoxin" (cds., Miller J. D., Trenholm, H. L.), p. 439-469 (1994), Eagan Press, St. Paul, MN.

20) Ehling, G., CockBurn, A., Snowdon, P., Buschhaus, H.: The significance of the Fusarium toxin deoxynivalenol (DON) for human and animal health. Cereal Res. Commun., 25, 443-447 (1997). 